\title{
Monitoring river pollution with high-resolution satellite images
}

\author{
P. Trivero, W. Biamino \& M. Borasi \\ Dipartimento di Scienze dell 'Ambiente e della Vita, \\ Università del Piemonte Orientale "Amedeo Avogadro", Italy
}

\begin{abstract}
The Bormida river basin is a strongly polluted rural area in North West Italy. The contamination has been caused by a chemical plant operating locally from 1892 to 1997 with ensuing heavy consequences on agriculture, animal life and human health. In the last few years, there has been an attempt to remove hazardous waste and improve the conditions of the site.

We have employed a method based on high-resolution visible and infrared satellite images, which is able to assess the environmental impact of water contamination, with the aim of monitoring river banks. This method quantifies the Normalised Difference Vegetation Index (NDVI) on crops located close to the river using remote-sensed data. In this way it is possible to assess the spatial and temporal progression of land contamination and thus to be able to have an understanding of how much the interventions aimed at improving the situation were effective.

The results obtained show that it is possible to assess the influence of water pollution along the entire valley: consequences are clearly visible up to $60 \mathrm{~km}$ downstream because of the great amounts of pollutants having been discharged.

This method has been tested using Quickbird imagery (spatial resolution $\sim 2.4$ $\mathrm{m} /$ pixel) and has been validated comparing the results with chemical measurements.
\end{abstract}

Keywords: remote sensing, water pollution, NDVI.

\section{Introduction}

Throughout the nineteenth century, growing industrialisation led European nations to improved economic wealth. It also caused new, widespread concerns: environmental issues became increasingly important. Words such as "ecology" and "ecosystem" were coined [1]. 
Factories began to use rivers as an inexpensive way to discharge waste. Local authorities issued laws to regulate various kinds of pollution in an attempt to protect the environment. In many instances, toxic substances were nevertheless released for many years, leading to strong contamination. Cases of strong contamination are usually caused by waste being spilled in small bourns. Because of the scarcity of water, concentrations can become high very quickly. When a flood takes place, pollutants move on to a wide area and cause soil contamination on the river banks. This happens also when river water is used for irrigation.

In this paper we present the case of ACNA, a chemical factory operating for more than a century in a mountain area located in North West Italy. Waste has been discharged in a small river, leading to severe pollution of waters and also soils.

For many years, this situation has been considered as a test site for various scientific studies aimed at improving the assessment methods and the remediation techniques. Different approaches to this problem can be found in literature.

Chemical analyses of water samples are used to assess the levels of pollution using various methodologies, such as High Performance Liquid Chromatography or Tandem Mass Spectrometry [2].

Similar analyses have been performed on soils, applying standard procedures defined by the Law or by laboratory practice. Procedures such as Inductively Coupled Plasma-Mass Spectrometry or X-ray diffractometry are useful; however they often require a specific sample preparation [3].

In last few years biomonitoring techniques have been applied, clearly showing the unhealthy status of both plant [4] and animal life [5] directly related to strong contamination.

Our approach uses remote-sensing techniques to monitor vegetation in the proximity of river banks. From the Normalised Difference Vegetation Index (NDVI), computed from visible and near-infra-red satellite images, it is possible to assess the conditions of vegetation along the water course; an unhealthy status can be related to biological stress caused by pollution.

Chemical measurements have been used for validation purposes. A "chemical index" has been defined, based on concentration of various toxic substances sampled in different places, and compared with NDVI assessed on same areas.

\section{Study area}

The Bormida watershed covers about 2,600 square $\mathrm{km}$ including the watershed of the Bormida di Millesimo, the Bormida di Spigno and the main stretch of the Bormida, from its source at $\sim 1400 \mathrm{~m}$ as far as its convergence with the Tanaro River after a $110 \mathrm{~km}$ course. It flows through 69 municipalities in 2 regions (51 in Piedmont, 18 in Liguria) with a total resident population of about 210,000. All branches of Bormida River are characterised by a very irregular flow, which is even close to zero during the summer. 
In 1892, agriculture was the main activity of the locals. It was then that a dynamite factory was founded in Cengio (on the Millesimo branch), on the border between the Piedmont and Liguria regions. After a few years, about 5000 workers were employed and the first environmental concerns began to appear.

In 1919, the factory was converted to produce colouring agents for a wide variety of industries. Agriculture was then abandoned locally because of the high levels of water pollution (not only in the river but even in wells). Vegetables and grapes, irrigated with water from the Bormida water, were reported to "smell of phenol". Epidemiological studies showed a high percentage of deaths caused by bladder cancer. Popular concern and unrest grew over the decades.

The entire area has been declared a "high risk area" in 1987 by the Italian Ministry of Environment. In 1998, the factory was closed after an accident had occurred. Great amounts of carcinogenic substances, such as phenol and dioxin, were found in the soil underneath the plant. Reclamation was soon started and is in progress.

Many studies on this problem have been carried out in the past. Indeed, many are still in progress, in order to explore hydrological and environmental features of Bormida River. National and local institutions conduct a systematic water quality monitoring programme to measure the extent of the damage to water resources caused by chemical and industrial plants [6,7].

\section{Survey methodologies}

Among the existing methods for surveying the territory crossed by the Bormida River, remote-sensing offers new possibilities for investigating and monitoring soil pollution. Compared with data obtained with traditional methods, satellite images supply an exhaustive view of vast areas at a low cost. The data stored in these images (both at visible and non-visible wavelengths) provide accurate information on ground conditions, especially when investigating vegetation stress. The spectral signature of vegetation depends on the physiological and biophysical status of the plants. Environmental stressors, such as heavy metals, produce alterations in plant biochemistry and cellular composition (and hence in the reflectance). These characteristics can be detected using remote sensors [8-13].

Vegetation indices are usually a combination between red $(\mathrm{R})$ and nearinfrared (NIR) channels, because these channels often contain more than $90 \%$ of the information relating to vegetation. These are quantitative measurements that have a better sensitivity in assessing the vigour of vegetation than individual spectral bands. NDVI is defined as:

$$
N D V I=\frac{N I R-R}{R-N I R}
$$

where NIR and $\mathrm{R}$ are wavelengths in the reflective infrared $(\sim 0.65-0.90 \mu \mathrm{m})$ and red $(\sim 0.60-0.65 \mu \mathrm{m})$ bandwidths, respectively.

NDVI is a ratio that varies between -1 and 1 , with only active growing vegetation having positive values [20]. 
NDVI is the best descriptor of vegetation variations because the normalization minimizes both the atmospheric effects and the radiometric degradation in the red and infrared bands [14]. Several studies have pointed out that NDVI values are representative of plants' photosynthetic efficiency (along with biomass concentration) $[15,16]$.

In the last few years, several studies have documented the usefulness of NDVI for assessing environmental pollution [17-19].

\section{Satellite data}

The remote-sensing data source analysed consisted of a high spatial resolution multi-spectral image, taken on November 17th 2003 by DigitalGlobe Quickbird satellite. The technical characteristics of Quickbird satellite are summarized in the table 1 .

Table 1: $\quad$ Characteristics of QuickBird satellite.

\begin{tabular}{|l|l|}
\hline Launch Date & October 18, 2001 \\
\hline Orbit Altitude & $450 \mathrm{~km}$ \\
\hline Orbit Inclination & 97.2 degree, sun-synchronous \\
\hline Equator Crossing Time & $10: 30$ a. m. (descending node) \\
\hline Digitization & 11 bits \\
\hline \multirow{4}{*}{ Resolution } & Pan: $61 \mathrm{~cm}$ \\
\cline { 2 - 2 } & MS: $2,4 \mathrm{~m}$ \\
\hline \multirow{5}{*}{ Image Bands } & Pan: $450-900 \mathrm{~nm}$ \\
\cline { 2 - 2 } & Blue: $450-520 \mathrm{~nm}$ \\
\cline { 2 - 2 } & Green: $520-600 \mathrm{~nm}$ \\
\cline { 2 - 2 } & Red: $630-690 \mathrm{~nm}$ \\
\cline { 2 - 2 } & Near IR: $760-900 \mathrm{~nm}$ \\
\hline
\end{tabular}

Figure 1 is a true colour composite image created by combining the QuickBird visible red (band 3), green (band 2), and blue (band 1) channels. It has a width of about $3.5 \mathrm{~km}$ and portrays a stretch of the Bormida River of about 20 $\mathrm{km}$ from Millesimo up to Monesiglio. The green areas represent the sampled fields analyzed in the next section.

Image analysis was carried out using the ENVI 4.2 image processing system (the Environment for Visualizing Images), a software package distributed by ITT Visual Information Solutions.

\section{Data analysis}

In order to assess heavy metal pollution effects on vegetation, the first task has been locating and masking the vegetated areas in the whole image. This task was performed using the Decision Tree classification method. This classifier carries 


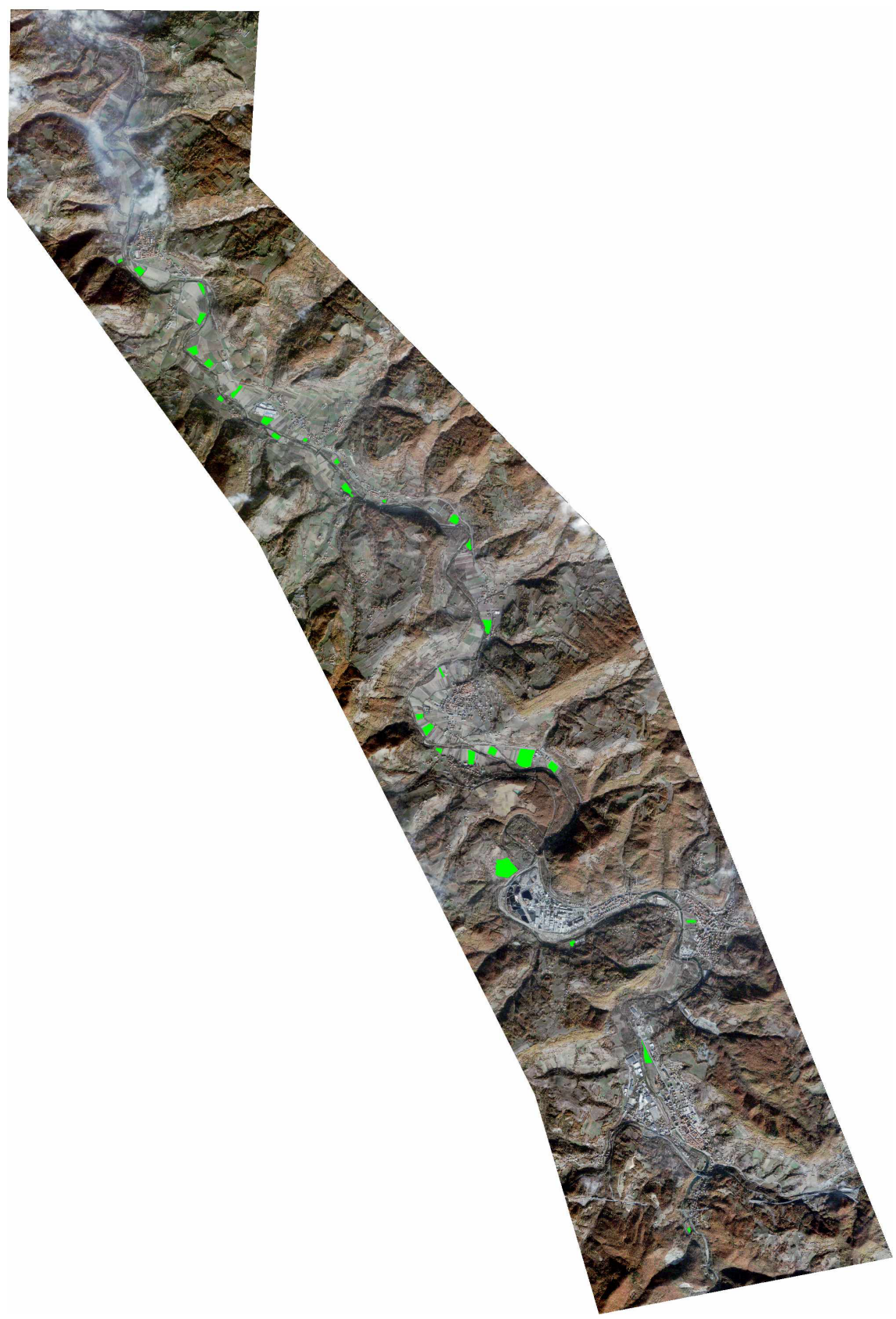

Figure 1: QuickBird image of the Bormida Valley (C) 2003, DigitalGlobe). The green areas highlight the sampled fields. 
out a multi-stage classification using a series of binary decisions to place pixels into different classes [21]. Four expressions, one for each band, were used as input of the classifier; these expressions quantify the reflectance ranges of a vegetated area. The reflectance values of a known vegetated area were used as a training dataset suitable for generating the classification.

After the classification, NDVI was used to transform multispectral data into a single image band picturing distribution of vegetation.

On the NDVI map, 29 fields were selected along the banks of the Bormida River (both upstream and downstream of the ACNA plant) and the NDVI mean value was computed for each sample.

The NDVI mean values trend (along the river versus distance from the ACNA plant) is represented with a red line in figure 2. The abscissa origin represents the ACNA factory position. The upstream and downstream distance from the factory is measured along the course of the river. NDVI values close to ACNA factory rapidly decrease until the 4th $\mathrm{km}$ upstream of the plant revealing an area with high levels of pollution. From the 4th $\mathrm{km}$ (a part from strong fluctuations), they tend to slowly increase.

In order to compare the NDVI mean values trend with chemical measurements, a chemical (CI) index was defined

$$
C I=\prod_{x_{i}>x_{0 i}} e^{-\frac{x_{i}-x_{0 i}}{x_{0 i}}}
$$

where $x_{i}$ are actual measured values of different metal ions obtained analysing soil samples on the river banks by Marengo et al. [3] and $x_{0 i}$ are the thresholds summarized in table 2 . Where thresholds are indicated as an interval, we have chosen the maximum values.

Only pollutants with concentration greater than threshold are considered in eqn (2).

Table 2: $\quad$ Toxic concentrations of metals in soil [22-24].

\begin{tabular}{|c|c|c|c|c|c|c|c|c|}
\hline Metal & $\begin{array}{c}\text { Chromium } \\
(\mathrm{Cr})\end{array}$ & $\begin{array}{c}\text { Nickel } \\
(\mathrm{Ni})\end{array}$ & $\begin{array}{c}\text { Copper } \\
(\mathrm{Cu})\end{array}$ & $\begin{array}{c}\text { Zinc } \\
(\mathrm{Zn})\end{array}$ & $\begin{array}{c}\text { Arsenic } \\
(\mathrm{As})\end{array}$ & $\begin{array}{c}\text { Cadmium } \\
(\mathrm{Cd})\end{array}$ & $\begin{array}{c}\text { Mercury } \\
(\mathrm{Hg})\end{array}$ & $\begin{array}{c}\text { Lead } \\
(\mathrm{Pb})\end{array}$ \\
\hline $\begin{array}{c}\text { Toxic threshold } \\
\left(\mathbf{m g ~ K g}^{-1}\right)\end{array}$ & $75-100$ & 100 & 100 & 300 & $20-50$ & 5 & $0,3-5$ & $100-400$ \\
\hline
\end{tabular}

CI, which can assume values between 0 and 1, summarizes the toxic effects of the whole metal ions: chromium $(\mathrm{Cr})$, nickel $(\mathrm{Ni})$, copper $(\mathrm{Cu})$, zinc $(\mathrm{Zn})$, arsenic (As), cadmium $(\mathrm{Cd})$, mercury $(\mathrm{Hg})$ and lead $(\mathrm{Pb})$. The chemical index is plotted with a blue line in the figure 2. Higher CI values correspond to lower levels of pollution. The graph shows a coherent pattern between the NDVI data and the CI mean values: high vegetation index values match the high chemical index values. 


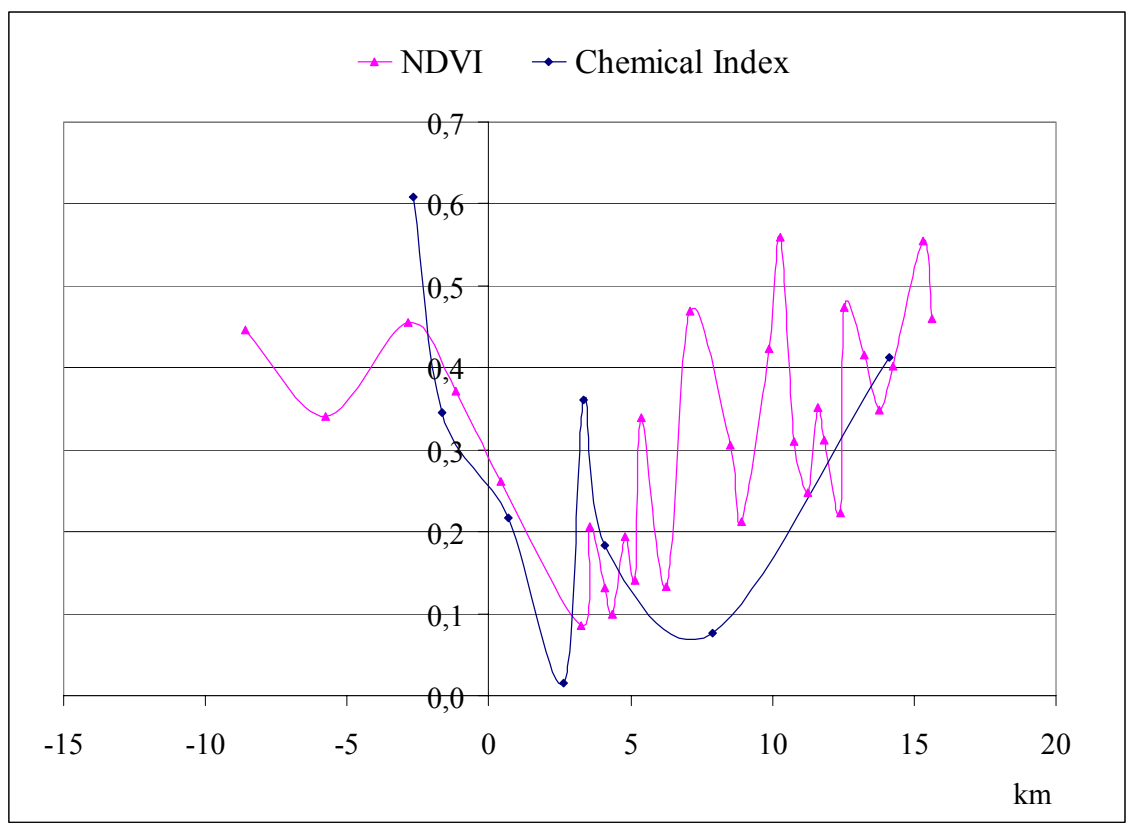

Figure 2: $\quad$ NDVI and CI versus distance from the ACNA plant.

\section{Conclusions}

Water pollution was assessed by evaluating NDVI on vegetated areas along the Bormida River and was found to affect a long section of Bormida valley. The rapid decrease of the index clearly shows that the ACNA chemical plant was responsible of pouring great amounts of pollutants.

NDVI values are in agreement with the chemical index defined by formula (2), which assesses the cumulative effect of eight toxic substances (chromium, nickel, copper, zinc, arsenic, cadmium, mercury and lead) in soil samples collected along the river banks.

All measurements point to the presence of strong contamination downstream the plant, even as far as several tens kilometres.

These results suggest that NDVI values obtained from satellite images can be used as an indicator of pollution caused by river waters, and they are therefore suitable as a survey tool for fluvial environment studies.

\section{References}

[1] Anker, P., Imperial Ecology, Environmental Order in the British Empire, 1895-1945, Harvard University Press, Cambridge, Massachusetts, London, England, 2001. 
[2] Zerbinati, O., Vincenti, M., Pittavino S. \& Gennaro, M. C., Fate of aromatic sulfonates in fluvial environment. Chemosphere, 35 (10), pp. 2295-2305, 1997.

[3] Marengo, E., Gennaro, M. C., Robotti, E., Rossanigo, P., Rinaudo, C., Roz-Gastaldi, M., Investigation of anthropic effects connected with metal ions concentration, organic matter and grain size in Bormida river sediments. Analytica Chimica Acta, Vol. 560, pp. 172-183, 2006.

[4] Vallino, M., Massa, N., Lumini, E., Bianciotto, V., Berta, G. \& Bonfante, P., Assessment of arbuscular mycorrhizal fungal diversity in roots of Solidago gigantean growing in a polluted soil in Northern Italy. Environmental Microbiology, 8 (6), pp. 971-983, 2006.

[5] Avidano, L., Gamalero, E., Cossa, G. P. \& Carraro, E., Characterization of soil health in an Italian polluted site by using microorganisms as bioindicators. Applied Soil Ecology, Vol. 30, pp. 21-33, 2005.

[6] Ministero dell'Ambiente, Relazione sullo stato dell'Ambiente, 2003.

[7] Ministero dell'Ambiente, Relazione sullo stato dell'Ambiente, 2005.

[8] Asner, G.P., Biophysical remote sensing signatures of arid and semiarid ecosystems (Chapter 2). Remote Sensing for the Earth Sciences, Vol. 4, eds. S. L. Ustin, John Wiley \& Sons, pp.53-109, 2004.

[9] Ustin, S.L., Smith, M.O., Jacquemoud, S., Verstraete, M. \& Govaerts, Y., Geobotany: vegetation mapping for earth sciences. Remote Sensing for the Earth Sciences, Vol 3, eds. A. Rencz, John Wiley \& Sons, pp. 189-248, 1999.

[10] Ustin, S.L., Smith, M.O., Jacquemoud, S., Zarco-Tejada, P.J. \& Asner, G.P. Remote sensing of the environment: state of the science and new directions (Chapter 13). Remote Sensing for the Earth Sciences, ed. S.L. Ustin, Vol. 4, John Wiley \& Sons, pp. 679-730, 2004.

[11] Wessman, C.A., Evaluation of canopy biochemistry. Remote Sensing of Biosphere Functioning, eds. R.J. Hobbs \& Mooney H.A., SpringerVerlag: New York, pp. 135-156, 1990.

[12] Woolley, J.T., Reflectance and transmittance of light by leaves. Plant Physiology, Vol. 47, pp. 656-662, 1971.

[13] Rosso, P. H., Pushnik, J. C., Lay, M. \& Ustin, S. L., Reflectance properties and physiological responses of Salicornia virginica to heavy metal and petroleum contamination. Environmental Pollution, Vol. 137, pp.241-252, 2005.

[14] Santos, T.G., Caetano, M.R., Barbosa, P. M. \& Paul, J. U., A comparative study of vegetation indices to assess land cover change after forest fires. Remote Sensing for Earth Science, Ocean, and Sea Ice Applications, Vol. 3868, pp. 232-240, 1999.

[15] Groten, S.M.E., NDVI-crop monitoring and early yield assessment of Burkina Faso. International Journal of Remote Sensing, Vol. 14, pp. 1495, 1993.

[16] Loveland, T.R., Merchant, J.W., Ohlen, D.O. \& Brown, J.F., Development of a land-cover characteristics database for the 
conterminous U.S. Photogrammetric Engineering \& Remote Sensing, Vol. 57, pp. 1453-1463, 1991.

[17] Fravretto, A., Mauro, G., Molinari, M. \& Davini, E., Analisi multitemporali su immagini telerilevate. Identificazione e mappatura dell'impatto sulla vegetazione derivante dalla presenza di idrocarburi nella falda. Studio di un'area campione. Conferenza nazionale ASITA, 2003.

[18] Virtanen, T., Mikkola, K., Patova, E. \& Nikula, A., Satellite image analysis of human caused changes in the tundra vegetation around the city of Vorkuta, north-European Russia. Environmental Pollution, Vol. 120, pp. 647-658, 2002.

[19] Zorzi, M., Dagnino, A., Delucchi, F., Dondero, F., Borasi, M., Cossa, G., Ariati, L., Trivero, P. \& Viarengo, A., Monitoring and risk assessment activities of exhausted rubbish dump characterized by a release of leachate in the superficial groundwater aquifer. Proc. Of the $10^{\text {th }}$ International Waste Management and Landfill Symposium, ed. CISA, Environmental Sanitary Engineering Centre: S. Margherita di Pula, Cagliari, Italy, 2005.

[20] Jelinski, D.E. \& Wu, J., The modifiable areal unit problem and implications for landscape ecology. Landscape Ecology, 11 (3), pp.129140, 1996.

[21] ENVI 4.2: User's Guide, ed. Research System: Boulder, USA, 2005.

[22] Kabata-Pendias, A., Trace elements in soils and plants, ed. CRC Press Boca Raton: Florida, pp. 394, 2001.

[23] Alloway, B.J., Heavy metals in soils, ed. Blackie, pp. 339, 1990.

[24] Álvarez, E., Fernandez Marcos, M.L., Vaamonde, C., Fernandez-Sanjurjo, M.J., Heavy metals in the dump of an abandoned mine in Galicia (NW Spain) and in the spontaneously occurring vegetation. The Science of the Total Environment, Vol. 313, pp. 185-197, 2003. 